\title{
Establishing a Robotic, LEO-to-GEO Satellite Servicing Infrastructure as an Economic Foundation for Exploration
}

Gary A.P. Horsham and George R. Schmidt

Glenn Research Center, Cleveland, Ohio

James H. Gilland

Ohio Aerospace Institute, Brook Park, Ohio 


\section{NASA STI Program . . . in Profile}

Since its founding, NASA has been dedicated to the advancement of aeronautics and space science. The NASA Scientific and Technical Information (STI) program plays a key part in helping NASA maintain this important role.

The NASA STI Program operates under the auspices of the Agency Chief Information Officer. It collects, organizes, provides for archiving, and disseminates NASA's STI. The NASA STI program provides access to the NASA Aeronautics and Space Database and its public interface, the NASA Technical Reports Server, thus providing one of the largest collections of aeronautical and space science STI in the world. Results are published in both non-NASA channels and by NASA in the NASA STI Report Series, which includes the following report types:

- TECHNICAL PUBLICATION. Reports of completed research or a major significant phase of research that present the results of NASA programs and include extensive data or theoretical analysis. Includes compilations of significant scientific and technical data and information deemed to be of continuing reference value. NASA counterpart of peer-reviewed formal professional papers but has less stringent limitations on manuscript length and extent of graphic presentations.

- TECHNICAL MEMORANDUM. Scientific and technical findings that are preliminary or of specialized interest, e.g., quick release reports, working papers, and bibliographies that contain minimal annotation. Does not contain extensive analysis.

- CONTRACTOR REPORT. Scientific and technical findings by NASA-sponsored contractors and grantees.
- CONFERENCE PUBLICATION. Collected papers from scientific and technical conferences, symposia, seminars, or other meetings sponsored or cosponsored by NASA.

- SPECIAL PUBLICATION. Scientific, technical, or historical information from NASA programs, projects, and missions, often concerned with subjects having substantial public interest.

- TECHNICAL TRANSLATION. Englishlanguage translations of foreign scientific and technical material pertinent to NASA's mission.

Specialized services also include creating custom thesauri, building customized databases, organizing and publishing research results.

For more information about the NASA STI program, see the following:

- Access the NASA STI program home page at http://www.sti.nasa.gov

- E-mail your question via the Internet to help@ sti.nasa.gov

- Fax your question to the NASA STI Help Desk at 443-757-5803

- Telephone the NASA STI Help Desk at 443-757-5802

- Write to: NASA Center for AeroSpace Information (CASI) 7115 Standard Drive Hanover, MD 21076-1320 
NASA/TM-2010-216937

AIAA-2010-8897

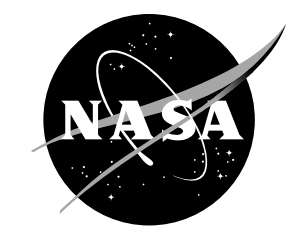

\section{Establishing a Robotic, LEO-to-GEO Satellite Servicing Infrastructure as an Economic Foundation for Exploration}

Gary A.P. Horsham and George R. Schmidt

Glenn Research Center, Cleveland, Ohio

James H. Gilland

Ohio Aerospace Institute, Brook Park, Ohio

Prepared for the

Space 2010 Conference and Exposition

sponsored by the American Institute of Aeronautics and Astronautics

Anaheim, California, August 30 to September 2, 2010

National Aeronautics and

Space Administration

Glenn Research Center

Cleveland, Ohio 44135 


\section{Acknowledgments}

The authors extend thanks to the following NASA personnel who contributed to this paper by providing a leadership framework, conducting workshops, and/or sharing opinions about the strategic business/technology future and potential of the emerging commercial in-space satellite servicing industry: Mr. Doug Comstock, Mr. Charles Miller, and Mr. David Huntsman, HQ; Dr. Bruce Webbon, ARC; Dr. Phillip Abel, Dr. Lynn Anderson, Dr. David Chato, Mr. Randall Furnas, Dr. Geoffrey Landis, Mr. Calvin Ramos, and Dr. Mary Zeller, GRC; Mr. Frank Cepollina, Mr. Benjamin Reed, Mr. Brian Roberts, Mr. Theodore Swanson, and Dr. Harley Thronson, GSFC; Mr. Edgar Zapata, KSC; Mr. John Dorsey and Dr. Judith Watson, LaRC; and Mr. David Smitherman and Dr. Philip Stahl, MSFC. In addition, the authors also extend thanks to the following industry and academia personnel: Dr. David Kang, MDA, and Dr. David Akin, UMD.

This report contains preliminary findings, subject to revision as analysis proceeds.

Level of Review: This material has been technically reviewed by technical management.

Available from

NASA Center for Aerospace Information 7115 Standard Drive

Hanover, MD 21076-1320
National Technical Information Service 5301 Shawnee Road Alexandria, VA 22312 


\title{
Establishing a Robotic, LEO-to-GEO Satellite Servicing Infrastructure as an Economic Foundation for Exploration
}

\author{
Gary A.P. Horsham and George R. Schmidt \\ National Aeronautics and Space Administration \\ Glenn Research Center \\ Cleveland, Ohio 44135 \\ James H. Gilland \\ Ohio Aerospace Institute \\ Brook Park, Ohio 44142
}

\begin{abstract}
The strategy for accomplishing civilian exploration goals and objectives is in the process of a fundamental shift towards a potential new approach called "Flexible Path." This paper suggests that a government-industry or publicprivate partnership in the commercial development of low Earth orbit to geostationary orbit (LEO-to-GEO (LTG)) space, following or in parallel with the commercialization of Earth-to-LEO and International Space Station (ISS) operations, could serve as a necessary, logical step that can be incorporated into the flexible path approach. A LTG satellite-servicing infrastructure and architecture concept is discussed within this new strategic context. The concept consists of a space harbor that serves as a transport facility for a fleet of specialized, fully- or semi-autonomous robotic servicing spacecraft. The baseline, conceptual system architecture is composed of a space harbor equipped with specialized servicer spacecraft; a satellite command, communication, and control system; a parts station; a fuel station or depot; and a fuel/parts replenishment transport. The commercial servicer fleet would consist of several types of spacecraft, each designed with specialized robotic manipulation subsystems to provide services such as refueling, upgrade, repair, inspection, relocation, and removal. The space harbor is conceptualized as an ISS-type, octagonal truss structure equipped with radiation tolerant subsystems. This space harbor would be primarily capable of serving as an operational platform for various commercially owned and operated servicer spacecraft positioned and docked symmetrically on four of the eight sides. Several aspects of this concept are discussed, such as: systemlevel feasibility in terms of ISS-truss-type infrastructure and subsystems emplacement and maintenance between LEO and GEO; infrastructure components assembly in LEO, derived from ISS assembly experience, and transfer to various higher orbital locations; the evolving Earth-to-orbit (ETO) capability to deliver humans and cargo to LEO for assembly purposes; system architectural definition, optimal orbital parameters, mass estimations, delta velocity $(\Delta V)$ estimations, power and propulsion options, and assessments of various critical technologies. Large-scale, robotic, LTG satellite servicing is considered as an essential economic pre-condition and next parallel or sequential step on the road toward exploration beyond LEO. Such a step might produce the necessary pre-requisite economic value that can be used by future decision makers to justify further investment in exploration beyond LEO.
\end{abstract}

\section{Introduction ${ }^{1}$}

The modern world remains extremely dependent on thin strings of several hundred civil, military, and commercial spacecraft/satellites currently stationed in space. They provide a steady stream of commerce, defense, and knowledge data. This dependency will in all likelihood increase significantly during this century. A major disruption of any kind in these essential systems and networks could be socially, economically, and politically catastrophic, on a global scale. The development of a space-based, robotic servicing economy could be useful in mitigating this growing risk, from an efficiency and security standpoint. This paper attempts to suggest what makes sense to invest in next for the logical, economic development of Earth orbit-i.e., after ISS completion. It incorporates results from recent NASA studies in 2010 to understand the barriers and challenges faced by U.S. industry and the formulation of a commercial business case (Refs. 1 and 2). It also expands on the results of early 2000s advanced market research and analysis studies (Ref. 3) that sampled the opinions of several satellite industry executives and presents these results within a broad policy context.

\footnotetext{
${ }^{1}$ This paper presents a revised strategic context and update of Reference 3 and includes a preliminary assessment and discussion of various key technologies.
} 
The concept of a "Space Harbor"2 (Fig. 1) that serves as the central component of a national, space-based or on-orbit/in-space, robotic or automated servicing infrastructure is introduced as the next logical step for United States leadership in space. This is viewed as a reasonable and appropriate follow-on to the development of expendable launch vehicles (ELVs) and satellites in the 1950s and 1960s, the Space Shuttle/partially reusable launch vehicle (PRLV) in the 1970s and 1980s, and the International Space Station (ISS) in the 1980s, 1990s, and 2000s. Large-scale experience in LTG spacecraft/satellite servicing and protection by robotic means is assumed to be a "stepping-stone" toward the development and preservation of the large scientific exploration facilities and humanrobotic exploration systems that are envisioned by NASA for operation beyond GEO. A balanced, return on national investment strategy for space, focused on the provision of enhanced national/homeland security for increased protection (from orbital debris and other threats), national economic/industrial expansion for increased revenue, and national scientific exploration for increased knowledge creates a strong goal in alignment with the new National Space Policy of the United States (Ref. 4). Satellite servicing is defined in this paper as the offering of services to owners or operators that involve the direct manipulation of on-orbit hardware or assets for the purposes of refueling,

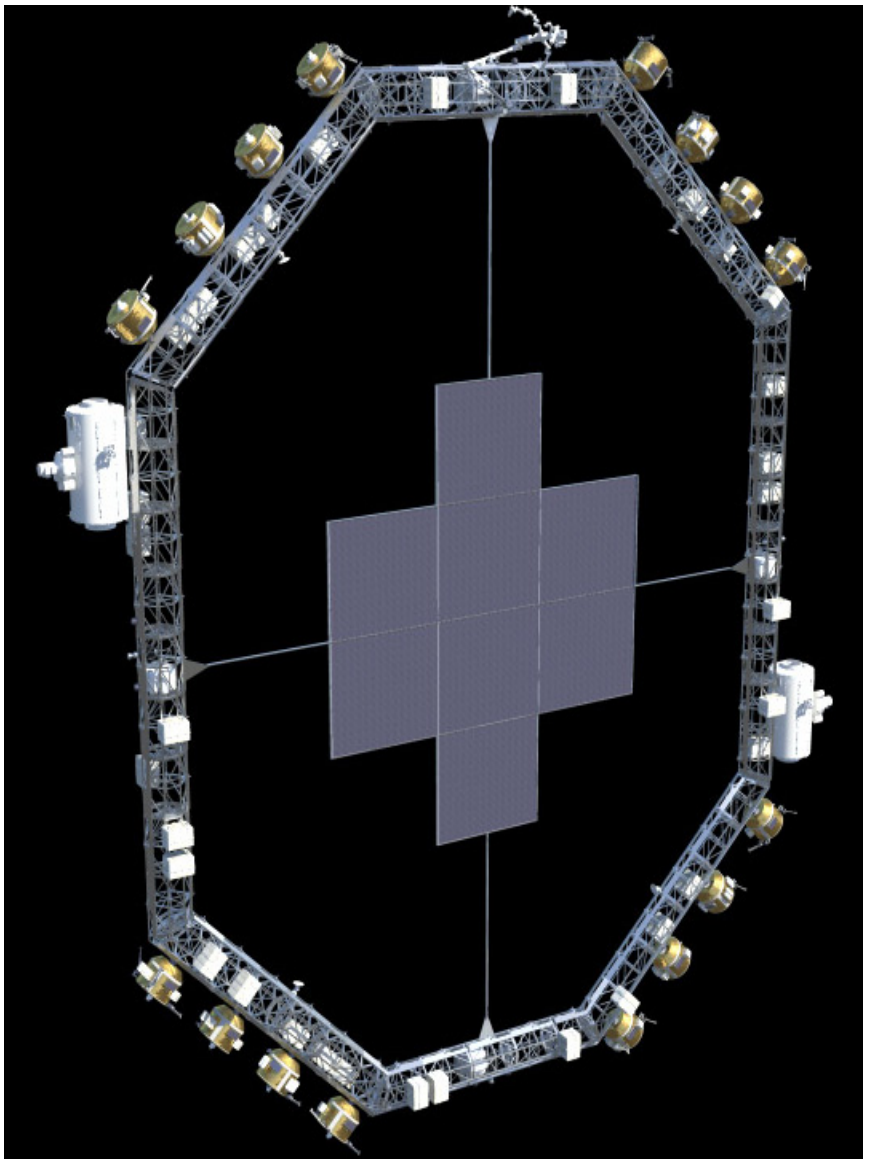

Figure 1.-Notional "Space Harbor" with 16 servicer spacecraft at a sub-GEO location. upgrade, repair, inspection, relocation, removal, etc.

The aforementioned NASA studies have resulted in the preliminary definition of five near-term "commercial inspace servicing" market sectors: (1) Propellant Transfer and Depot/Storage; (2) Satellite Servicing (i.e., Repair, Maintenance, Refueling, etc.); (3) Orbital Transportation/Transfer; (4) On-orbit Assembly; (5) Orbital Debris Removal/Mitigation. This paper presents a discussion of the long-range prospects for spacecraft/satellite servicing and protection by robotic means (i.e., by teleoperated remote control and/or full-autonomy) as a common government-industry strategy for the logical, systematic development of space beyond LEO.

Two key premises underlie this paper. Firstly, in the latter half of the 20th century, the feasibility of a LEO humans-in-space-centered space operations program was tested. The results-to-date indicate that the real and perceived benefits of having people in space need to heavily outweigh the risks inherent in transporting, keeping them there, and returning them to the Earth. Space, in terms of the LTG economic operations zone, or the beyond GEO exploration zone, appears to be the domain of semi- (i.e., teleoperated) and fully-autonomous (i.e., artificially intelligent) robots. Secondly, any major strategic/long-range exploration agenda will remain politically vulnerable and unsustainable without the establishment of a viable economic foundation.

This paper offers a vision and definition of a logical and rational future state, stepping stone, or intermediate destination point that takes into consideration the present space-related social, technological, economic, environmental, political, and scientific context of the United States. It suggests the notion of the full-fledged development of a space-based/on-orbit infrastructure that can support the creation of a robust, in-space, robotic satellite servicing enterprise. Such a capability could significantly augment and benefit NASA's exploration plans and begin the process of establishing an economic foundation to enhance sustainability and affordability of deeper

\footnotetext{
${ }^{2}$ The term "Space Harbor" was conceived as an appropriate, functional metaphor for the concept being introduced in this paper. Subsequent research revealed that the early 1980s Space Station Task Force, Concept Definition Team, had originally applied this metaphor to the LEO, human-tended, space station concept.
} 
space investments and activities into the future. The lack of an economic foundation can be considered the missing pre-requisite that has resulted in the failure of past exploration pronouncements to take hold-i.e., from the 1989 space exploration initiative (SEI) to the 2004 Vision for Space Exploration (VSE). The new national space policy, which is interpreted as a formalization of the "Flexible Path" or "Flex Path" approach (Ref. 5), emphasizes the need for a real and significant involvement of private commercial interests and international partners-beginning now and extending indefinitely into the future. It is possible that vigorous, White House level emphasis on these critical success factors will lead to a new national and international paradigm or mindset shift needed for real sustainability.

Five sections follow this introduction. Section II, discusses the LTG infrastructure system concept and how it might fit within a logical space development framework. Section III presents a notional assessment of the LTG system construction and operation, with a focus on electric propulsion and technology, and robotic communications and control. Section IV discusses the emerging satellite servicing industry and national investment within an historical context; the status of the commercial satellite industry; and then offers a high-level roadmap for potential forward action through a government-commercial partnership. Section $\mathrm{V}$ assesses alignment with the new national space policy. Finally, Section VI offers a concluding statement.

\section{LEO-to-GEO Infrastructure System Concept}

Figure 2 (shown in the previous section) presents a high-level, LTG satellite-servicing infrastructure concept. ${ }^{3}$ At the heart of this concept is a space harbor that serves as a "basing" facility for a fleet of market specialized automated servicing and protection spacecraft (SASPS). This fleet could consist of several spacecraft, each one specially built to provide a service in one market segment such as: refuel, upgrade, repair, inspection, relocation, removal, threat interception, threat neutralization, etc. (Fig. 3). The space harbor is considered to be octagonal in shape with docking stations for each servicer spacecraft positioned symmetrically on four of the eight sides. The baseline, conceptual system is composed of the following:

1. Two Space Harbors each equipped with 16 specialized servicer spacecraft. (Fig. 1)

2. A satellite command, communication, and control $\left(\mathrm{C}^{3}\right)$ system

3. A Fuel Station (Depot) (Fig. 4)

4. A Parts Station (Fig. 5)

5. A Fuel/Parts Replenishment Transport

Figure 6 shows a notional servicing mission to a GEO communications satellite. With autonomous rendezvous and docking interface and other standards accepted internationally, these servicer spacecraft could conceivably be built, owned and/or operated by numerous private companies from any country in the world — somewhat similar to today's commercial satellites model. The goal of this logic would be to build a strong "economic foundation" with the aim of achieving economic ROI in support of NASA's beyond-GEO exploration strategy.

The LTG region is currently the only accessible, extraterrestrial region with both near and far-term civil, military, and commercial development potential. The initial exploitation of this potential began with the 20th century installation of numerous communications satellites and other spacecraft in orbits throughout the region. The Van Allen radiation belts dominate the region and produce a very harsh environment that challenges the survivability of both humans and machines. Several key technology areas such as low temperature and radiation tolerant electronics, laser/optical communications, and space robotics, are all at medium-to-high levels of maturity. In this regard, the LEO-to-GEO domain is perhaps also the only accessible region in space with any reasonable potential for achieving increasing relevance and value to the economy of the United States and the world during the 21 st century.

Figure 7 depicts the stepwise progression of space systems and capabilities development from ELVs and satellites in the 1950s and 1960s, to the shuttle/PRLV in the 1970s and 1980s, then to the ISS in the 1980s, 1990s, and 2000s. The next logical step in early 21 st century U.S. (and international) space strategy should perhaps focus on establishing a "spacecraft harbor or carrier"-centered, national infrastructure. Progress in this systematic manner would establish a strong economic and experiential foundation upon which the planned exploration strategy beyond LEO and GEO can be built.

\footnotetext{
${ }^{3}$ This concept was formulated in 2003 and published in Reference 3. If feasible and cost effective, policy changes could result in system establishment during the first or second quarter of the 21 st century.
} 


\section{LEO-to-GEO Infrastructure System Concept}

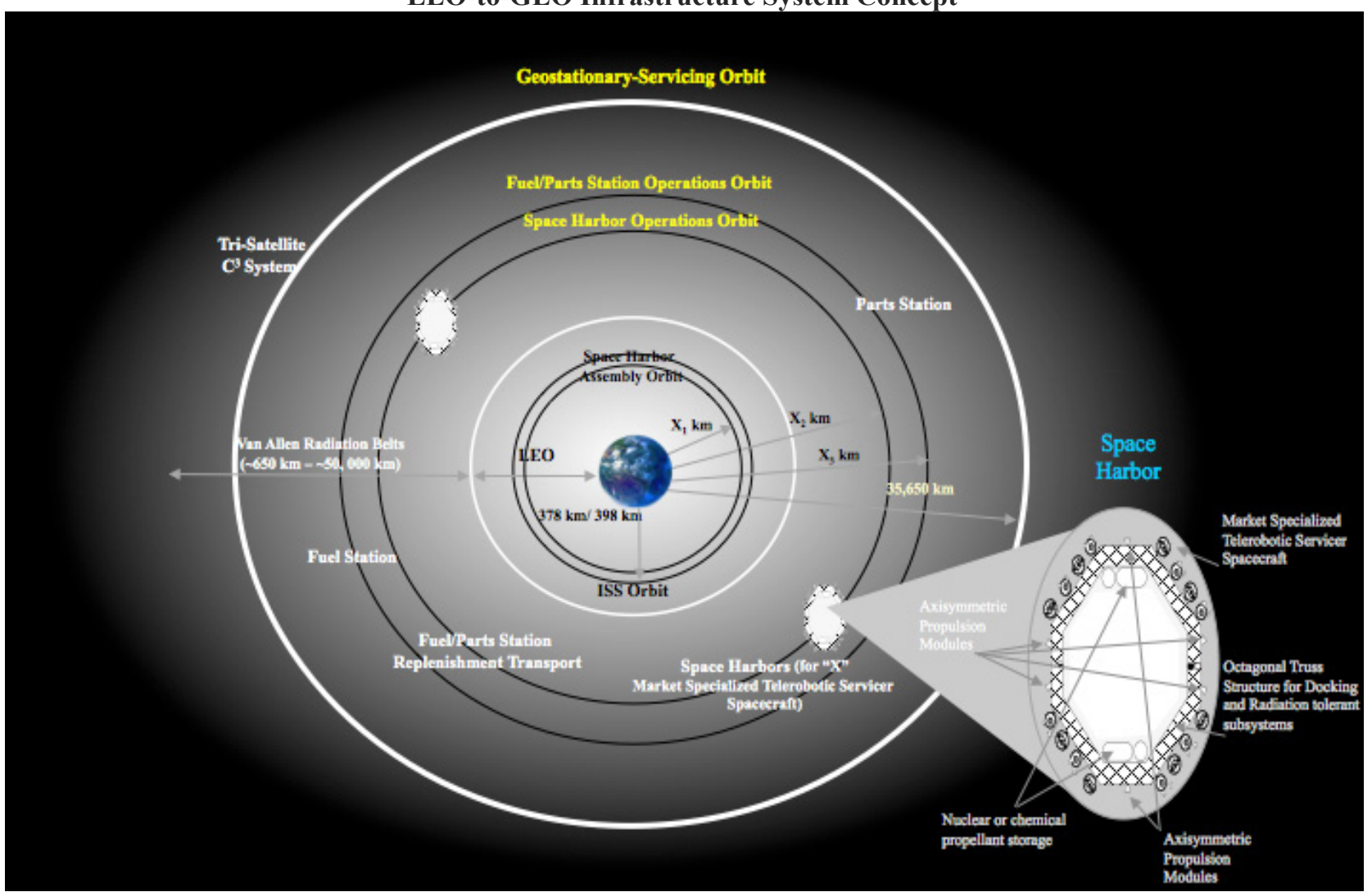

Figure 2.-A LTG robotic servicing architecture concept can be a logical, systematic follow-on capability to the ISS. It would require a government-led initiative, preferably spearheaded by a transformational, civil-militarycommercial partnership. This would help build a sturdy economic foundation or building block for space development and exploration. ("X" indicates an unknown quantity, which can be determined and optimized via an analysis that takes into consideration the orbital debris and radiation belt environments).

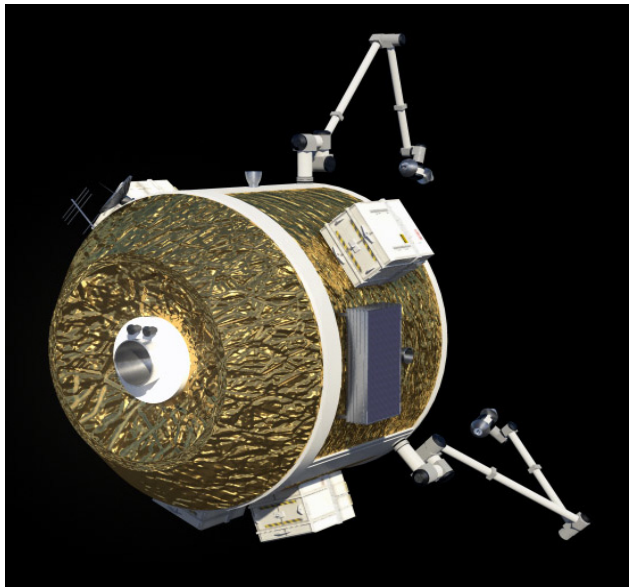

Figure 3.-Notional servicer spacecraft.

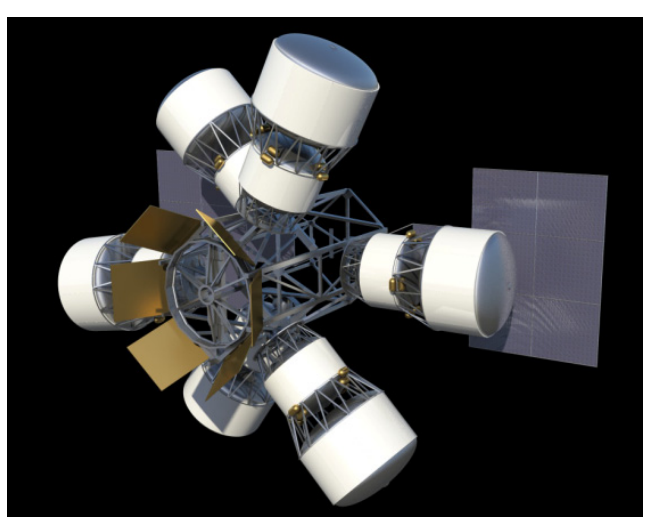

Figure 4.-Notional fuel station. 


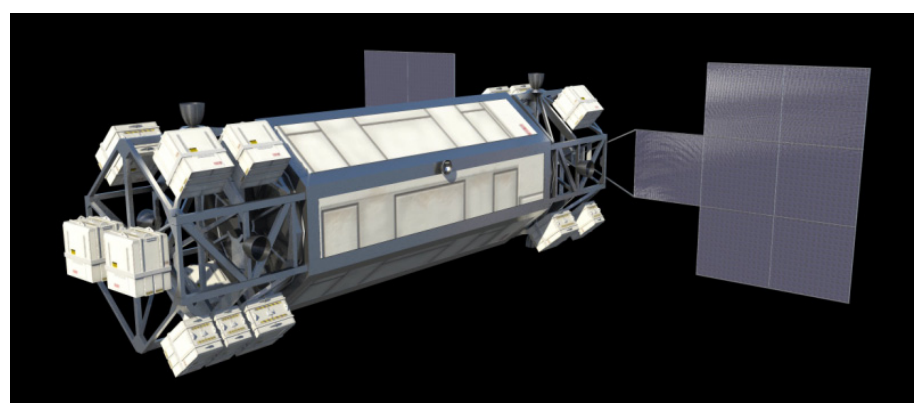

Figure 5.-Notional parts station.

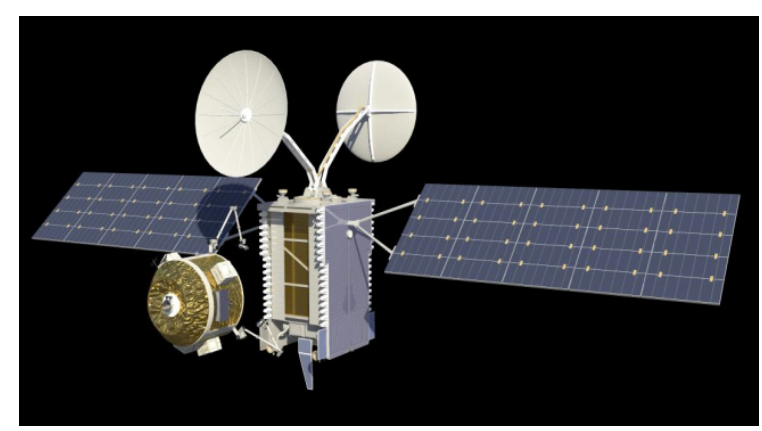

Figure 6.-Notional servicer spacecraft performing a servicing mission on a GEO communications satellite.

$\begin{gathered}\text { Build a New Industry Infrastructure as an } \\ \text { Economic Foundation for Exploration }\end{gathered}$
$\begin{gathered}\text { LTG Servicing Infrastructure } \\ \text { Developmentioperations }\end{gathered}$ Economic Foundation for Exploration

ISSiSpace Station
Development/Operations

PRLV/Shuttle STS

Development/Operation

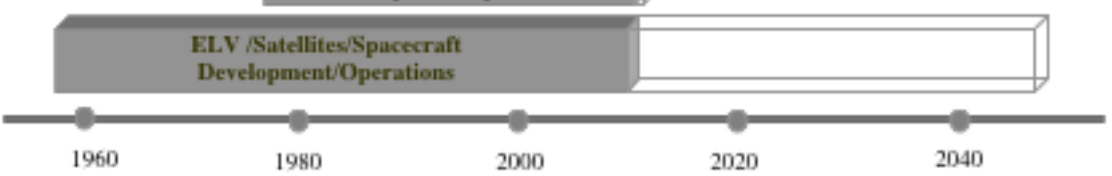

Figure 7.-The next logical step in early 21 st century US (and international) space strategy should perhaps focus on establishing a "spacecraft harbor or carrier"-centered, national infrastructure following the NASA STS and ISS investments. 


\section{System Construction and Operations}

As discussed in Section II, the large-scale, robotic, LTG satellite-servicing infrastructure concept consists of a "space harbor" for a fleet of SASPS. One version of a potential space harbor is considered to be octagonal in shape with docking stations for each servicer spacecraft positioned symmetrically on four of the eight sides. The core space harbor subsystem of the LTG satellite servicing infrastructure system is conceptualized based on the U.S. ISS heritage. It is notionally constructed from ISS-P3/P4 truss assembly elements (length $=13.8 \mathrm{~m}$; width $=4.8 \mathrm{~m}$ ) ${ }^{4}$ The two shorter parallel sides each contain 3 sections, the two longer parallel sides each contain 6 sections, and the four remaining $45^{\circ}$ angled sides each contain 4 sections. This would result in a notional length of $160 \mathrm{~m}$ and width of $119 \mathrm{~m}$. Construction of the LTG infrastructure is planned for a circular, co-planar "space harbor assembly orbit," at a safe, close LEO distance in the vicinity of the present ISS orbit. The following assumptions underlie this concept:

1. An ISS-truss-type infrastructure and subsystems can be effectively and efficiently emplaced and maintained between LEO and GEO.

2. Components of this infrastructure can be assembled in LEO (in a similar manner to the ISS), as necessary, and then transferred to various higher orbital locations.

3. An efficient and effective Earth-to-orbit (ETO) capability will be available to deliver humans and cargo to LEO.

A complete pre-phase A feasibility study of this concept would entail the following analyses:

A. Basic analyses:

1. System-level feasibility

2. Architectural definition

3. Cost analyses

B. Supplementary analyses:

1. Optimal orbital parameters: $X_{1}, X_{2}, X_{3}$ (see Fig. 2)

2. Mass estimations

3. Delta $\mathrm{V}$ estimations

4. Comparison of chemical and electric systems

5. 3D Modeling and Simulation

6. Critical technologies

- Telerobotics, On-orbit Assembly/Disassembly, Inter and Intra-Orbital transfer and Insertion, Autonomous Rendezvous and Docking, Low Thrust Electric/Chemical Propulsion, Power Generation and Energy Storage, Low Temperature/Radiation Hardened Electronics, High Data Rate Communications, Broadband Satellite Communications, Cryogenics, In-Space Fuel Transfer and Storage, etc.

A preliminary assessment of electric propulsion operations and the technological state-of-the-art (SOA) are discussed in the two sub-sections below.

LTG satellite servicing operations are envisioned to be conducted from an optimized sub-GEO location that will be determined by taking into consideration radiation and debris environments, and other factors - such as time-torendezvous. Operations will involve telerobotic or supervised autonomy control of servicer spacecraft by operators on the ground. The satellite command, communication, and control subsystem requirement would not require any new hardware to be launched and would instead rely on existing commercial communication satellite assets already in service at GEO. An overview of in-space robotics communications and control operations is presented in the Appendix.

\section{A. Electric Propulsion Operations}

Routine in-space servicing might eventually consist of a series of established orbiting stations housing remote specialized automated servicing and protection spacecraft or servicer spacecraft. The servicer spacecraft will require adequate mobility to reach the target satellite client population, as well as possible derelict debris craft that must be removed. This introduces a complex optimization problem, dealing with the proper staging orbits, the optimal propulsion system parameters, the number of servicer spacecraft, and the allowable number of trips per servicer spacecraft, which are all free parameters to be determined.

\footnotetext{
${ }^{4}$ http://en.wikipedia.org/wiki/Integrated_Truss_Structure\#P3.2FP4.2C_S3.2FS4_truss_assemblies
} 


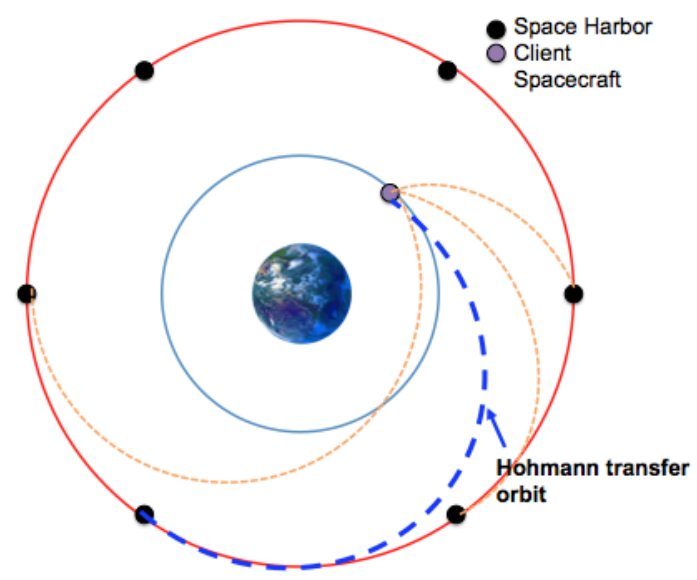

Figure 8.-Notional orbital transfer options for multiple node LTG servicing infrastructure.

In contrast to orbit transfer, which only primarily deals with transportation to a given orbital altitude and inclination, servicing will require rendezvous to the specific orbital altitude, inclination, and true need, problem or anomaly of the spacecraft to be serviced. The initial need or anomaly, and altitude of the servicing nodes, in combination with the trip time required for orbital transfer, will determine the vehicle that can rendezvous in the minimum time. A greater number of vehicles will yield lower propellant requirements, at the expense of additional hardware launched and maintained to the service orbit. A graphical example of the trades inherent is shown in Figure 8. This depicts a scenario with six space harbors located at a high basing orbit, servicing a satellite at an inner orbit. While multiple servicer spacecraft can reach the client spacecraft, only one can be done with the minimum propellant. Equivalently, one other spacecraft can reach the client in the minimum time. These trends hold true for the opposite case, in which the clients are at a higher orbit, such as GEO, than the space harbors.

A Hohmann transfer is the minimum $\Delta V$ trajectory, which requires a $180^{\circ}$ elliptical transfer between orbits. This type of transfer is labeled in Figure 3. For a Hohmann transfer between geosynchronous orbit and a $500 \mathrm{~km}$ orbit, the trip time would be 5 days using high thrust propulsion. This timing would have to be taken into consideration for determining the service vehicle to launch in order to minimize propellant. Shorter trip times would result in increased propellant requirements, and a different staging location for the service vehicle.

In the case of electric propulsion, the trade space extends to the variation in travel time due to the propulsion system power, specific impulse $\left(\mathrm{I}_{\mathrm{sp}}\right)$, and efficiency. Trip time affects the time to rendezvous, which then identifies the optimum service location from which to launch the service vehicle. An iterative approach to infrastructure design using electric propulsion requires taking the effects of power levels, and power and propulsion system masses, into the relationship. For electric propulsion orbital transfer, the orbit-to-orbit $\Delta V$ is a function of the circular orbits of the initial $\left(V_{1}\right)$ and final $\left(V_{2}\right)$ orbits:

$$
\Delta V^{2}=V_{1}^{2}+V_{2}^{2}-2 V_{1} V_{2} \operatorname{Cos}\left(\frac{\pi}{2} \Delta i\right)
$$

However, the above relation does not include the requirement to rendezvous at a specific point on the orbit, which will determine the choice of space harbor from which to launch a servicer spacecraft.

The trip time for the low thrust is dependent on the on board power system and the thruster performance. An example of this sensitivity is shown in Figure 9, where trip times from the space harbor to various lower orbits are shown as a function of power. Trip times are significantly lower than chemical, at the same power lever, for the full range of powers. The benefit, of course, is the increased payload capability for multiple rendezvous/servicing operations. Not included in this initial sensitivity study is the effect of $I_{\text {sp }}$ on the trip time. In addition, the actual delivered payload (i.e., servicing/refueling equipment and supplies) has not been identified; both the power and $\mathrm{I}_{\mathrm{sp}}$ will affect this number. 


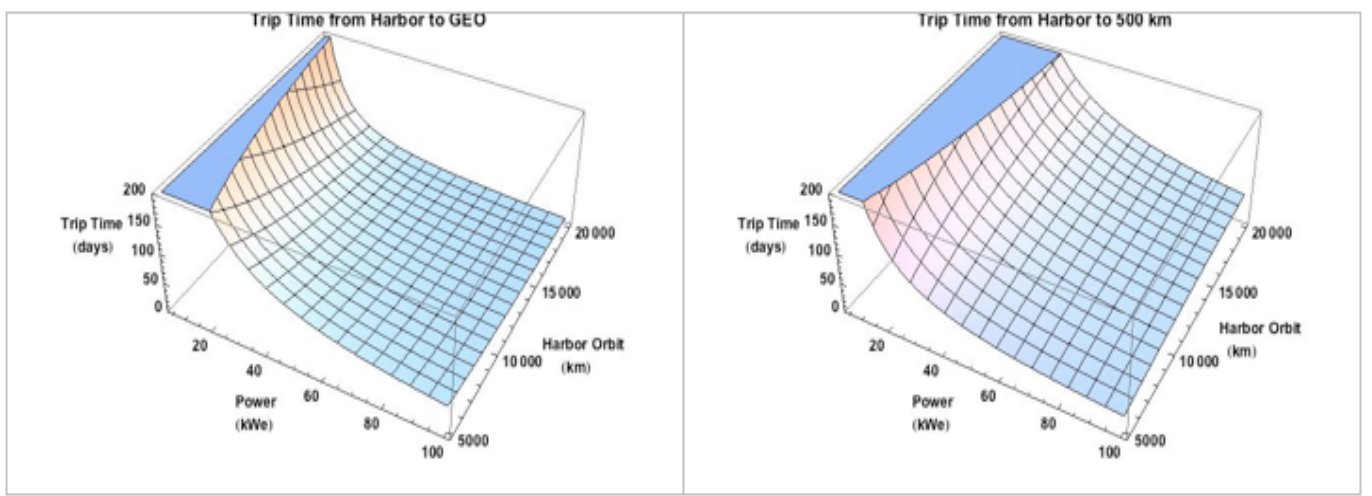

Figure 9.-Orbit transfer trip time sensitivity of low thrust systems to power level and space harbor orbital altitude.

TABLE 1.-SUMMARY OF SOLAR ELECTRIC PROPULSION STATE-OF-THE-ART, TECHNOLOGY READINESS LEVELS, AND TECHNOLOGICAL CHALLENGES

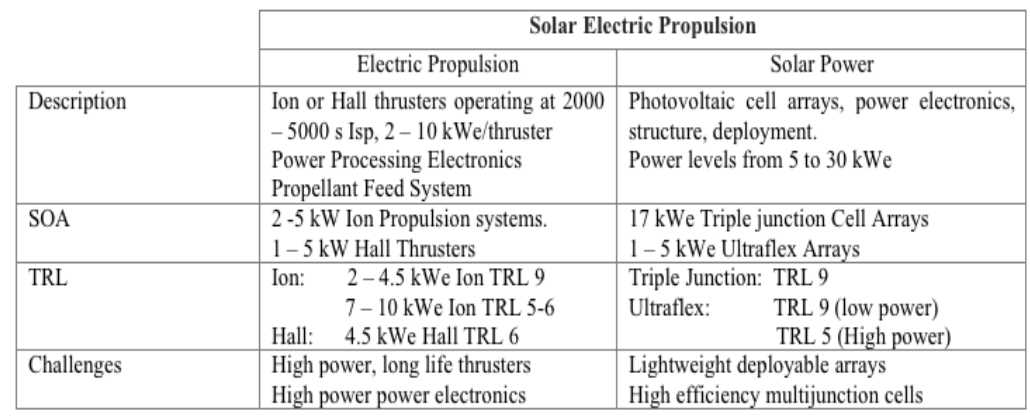

\section{B. Electric Propulsion Technology}

Table 1 presents a summary of electric propulsion and solar power SOA, Technology Readiness Levels (TRLs), and technological challenges.

Electric propulsion technology as an overall concept is currently at a TRL of 9, with routine use of ion and Hall thrusters on Earth orbiting satellites, and the successful flights of Deep Space 1 (ion), SMART1 (Hall), and Hayabusa (ion) beyond Earth orbit. These devices have operated at powers less than $5 \mathrm{kWe}$ per thruster, which, based on initial results shown in Figure 4, may not be sufficient for timely servicing.

The NASA developed NEXT ion propulsion system is at a TRL level of 5-6, with many of the components having gone through flight qualification testing (Ref. 6). This system is capable of operating at up to $10 \mathrm{kWe}$ per thruster (Ref. 7) Laboratory Hall effect thrusters have been operated up to $100 \mathrm{kWe}$ power levels, by both NASA (Ref. 8) and industry (Ref. 9). Key challenges remaining at the higher power levels are the power processing electronics and heat management of the overall propulsion system. Higher power systems are possible with further research (Ref. 10).

Solar power has reached the $17 \mathrm{kWe}$ levels on the Boeing 702 spacecraft (Ref. 11); however, the solar power systems are relatively massive for propulsion. More advanced power options include the UltraFlex and SLASR systems (Refs. 12 and 13). The UltraFlex array already has flight heritage for NASA science missions at low powers. Higher power, lightweight solar arrays using this technology have been considered in multiple NASA studies for planetary science missions using SEP. The structure, deployment, and space qualification of larger arrays remains the primary technology development effort. For more advanced arrays using high efficiency photovoltaics, the performance and manufacture of the cells remains a research topic.

\section{Emerging LEO-to-GEO Satellite Servicing Industry Sector}

From a commercial point of view, the development and utilization of LTG space has been underway since the early 1960s. The satellite industry presently consists of a mix of integrated services and applications sectors that include: Communications, Remote Sensing, GPS/Navigation, Broadband, Direct Broadcast System/Digital Audio Radio System (DBS/DARS). The industry's production sectors include: Ground Equipment, Launch Industry, Satellite Manufacturing, and Satellite Services. World satellite revenues (Ref. 14) as of June 2010 


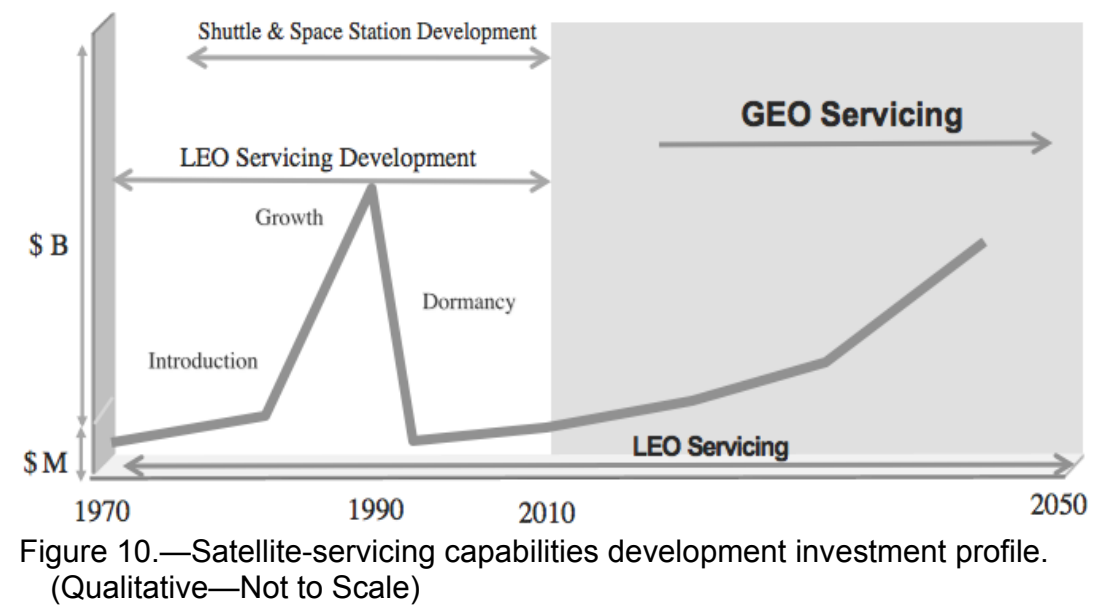

stood at $\$ 160.9$ billion, up from $\$ 82.7$ billion in 2004 for an average annual growth of 11.7 percent. This is a very positive trend that bodes well for the future of an industry that could be augmented by the advent of a satellite servicing capability that could result in lower industry risk, insurance premiums, and operating costs.

Figure 10 shows a qualitative satellite servicing capabilities development investment profile. Investment peaked in the mid-to-late 1980s due to space shuttle operations related to satellite servicing. The practicality of a satellite in geostationary orbit was first envisioned in the 1940s. The satellite industry (in particular the "communications" segment) has contributed positively to international trade, and has become indispensable to the terrestrial national and global security and economic infrastructure. The satellite industry was effectively born in the early 1960s and became dominant during its "introductory" stage in the 1960s and 70s when copper wire cable technology (a nineteenth century technology that enabled long distance and transoceanic, telegraph communications) entered its decline. Now in its "mature" stage, satellite technology (i.e., transponders) is threatened by the 1980s and 1990s emergence of challengers in the form of optical fiber cable and terrestrial wireless technologies. In addition to the challenging U.S. export control environment, the emergence of serious challengers during maturity has prevented the industry from reaping healthy returns on its investment (Ref. 15). Most importantly though, perceived high risk and the accompanying high insurance premiums ranging from 10 to 30 percent over time (Ref. 16), have combined to negatively impact this sector's market power. In December 2009, it was stated that the space insurance market had been very profitable over the last five years, and that this will inevitably lead to more competitive premiums for satellite operators. ${ }^{5}$

Figure $11^{6}$ presents an approximation of the evolutionary substitute/complementary telecommunications technology life-cycle market context within which in-space servicing emerged and could establish its niche (the thick line corresponds to the line in Fig. 10). It suggests that satellite and terrestrial technologies will become perfect complements and co-exist synergistically into the future.

Within the last decade, there were several high-profile, beginning of life (BOL) satellite failures, which may have been salvageable if the nation and the world were in possession of a robust, space-based servicing capability. There are strong indications that operators may be willing to invest in a servicing mission at beween 25 to 60 percent of total asset value, including launch cost, and that this fraction would tend to the high end of the range depending on proximity to $\mathrm{BOL}$ and the particular servicing objective. ${ }^{7}$ If validated through further studies, then it would be mutually beneficial for government and industry to join forces and define a common, "build-launchoperate-service-protect" (BLOSP) strategy that expands this important industrial capability while opening up the development of space. The creation of a satellite or spacecraft servicing industry sector could be that initial, common strategy.

\footnotetext{
${ }^{5}$ http://www.allbusiness.com/insurance/aviation-insurance-spacecraft-satellite/14534089-1.html

${ }^{6}$ Global market presence provides a qualitative picture of the relative impact, influence, and dominance a complementary or substitute technology/system has had in the global marketplace over time. Market presence can perhaps be quantified by determining the actual industry capitalization of each respective technology. Further quantitative analyses of this sort would increase the fidelity and accuracy of this qualitative picture. That was beyond the scope of this study.

${ }^{7}$ Reference 3, Appendix B, Question 16
} 


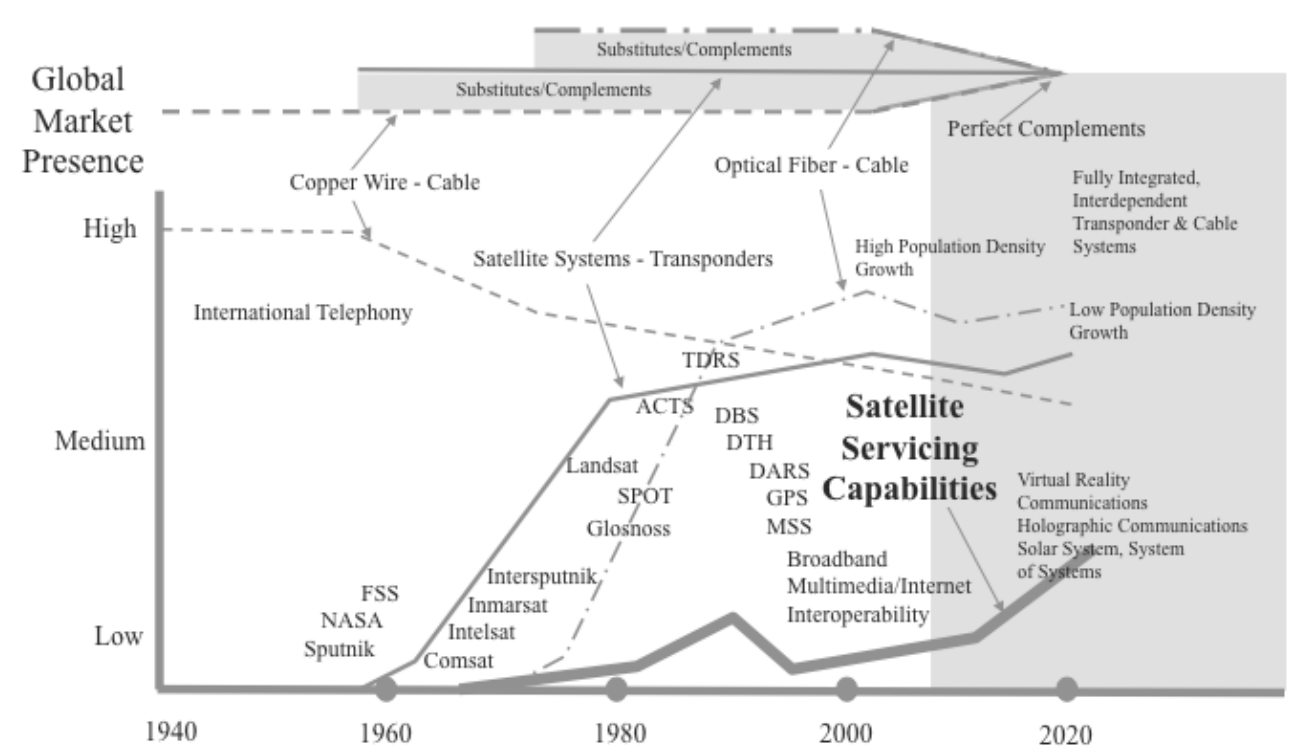

Figure 11.-Approximation of the evolutionary telecommunications technology life-cycle market context within which in-space servicing emerged and could establish a niche.

The existence of a thriving satellite industry offers an excellent opportunity for effective implementation of a government-industry, space-based, economic growth and capital infrastructure expansion strategy. Standardization, however, appears to be the key to any economic expansion of this industry due to its inherent cost-effectiveness. ${ }^{8}$ If standardization were to become an industry practice, new markets and private capital investment could ignite and propel the integrated, civil, military, and commercial development of LTG to a new level of performance. Another cost-effectiveness factor is international cooperation for cost sharing, especially where common goals and objectives are found. Although not as economically efficient as standardization, in the near-term, "uncooperative" satellite servicing technologies/capabilities are under development and will probably be applied first to effectively jump-start the new industry.

\section{A. Status of In-Space Satellite Servicing Industry}

The capability to service satellites began with the demonstration of the first U.S. extravehicular activity (EVA) on the Gemini 4 mission in June 1965. The technological development of human/robotic satellite servicing has been pursued since the1970s and came to a high point with a series of capability demonstrations (see Fig. 5). With the advent of the space shuttle space transportation system (STS) in 1981, satellite servicing, as a discipline, formally entered the public's consciousness.

In April 1984, the term "satellite servicing" was introduced with the retrieval, repair, and redeployment of the Solar Maximum Mission (SMM) satellite. The STS 41-D SMM satellite-servicing mission was very successful. Shortly after, in October that same year, astronaut, on-orbit refueling was demonstrated. In November 1984, the Westar and Palapa communications satellites were captured and returned to Earth. Space robotics, a key enabling technology for satellite/spacecraft servicing received considerable international and U.S. government investment during the 1980s, from the Canadian robotic manipulator system (RMS) for the STS and ISS, to a formal NASA space telerobotics program. The European Space Agency (ESA), led by the German Space Agency (DLR), has continued significant development of telerobotic/satellite servicing technologies.

Compared to 1980s spending levels, the development of U.S.-led, robotic, space-based servicing technology development entered a period of virtual dormancy throughout the 1990s. This was perhaps largely attributable to downsizing of the space station program and the general restructuring of the entire United States space program and aerospace industry (Ref. 17). There has been a reversal of this trend since 2004 when preparations began at NASA Goddard Space Flight Center (GSFC) for a robotic servicing mission to the HST-Servicing Mission (SM)-4. Although the planned, teleoperated HST-SM-4 was abandoned in favor of an astronaut-servicing mission, which was successfully completed in 2009, NASA retained and enhanced its robotic technology development capabilities

\footnotetext{
${ }^{8}$ Aggregated finding from Industry Briefings presented to the NASA Office of the Chief Technologist, Commercial In-Space Servicing Working Group, July 2010; and, Reference 3, Appendix B, Questions 8, 18, 19.
} 
and has been developing several "last-mile" technologies such as refueling valves that would allow refueling of uncooperative satellites.

Government-led, civil and military development of satellite servicing capabilities have progressed to the point where it is appropriate to assess the technical feasibility of a robust, large-scale, robotic, LTG servicing infrastructure. NASA GSFC is developing telerobotic systems for servicing scientific spacecraft such as the current HST. This capability is considered extensible to telerobotic LTG satellite servicing. DARPA's past (2007) Orbital Express/ASTRO and current Front-end Robotics Enabling Near-term Demonstration (FREND) programs have provided and will provide, respectively, several important demonstrations. The goal of the FREND program is to develop, demonstrate and fly robotic manipulator technologies designed to allow interaction with geosynchronous orbit (GEO)-based military and commercial spacecraft, extending their service lives and permitting satellite repositioning or retirement.

Between 1984 and 1990, NASA's attention was focused on the development of a "commercial" satellite servicing facility (SSF) and a flight telerobotics servicer ${ }^{9}$ (FTS) as major business components of the core space station system. The SSF was abandoned, however, for three apparent reasons: (1) inherent incompatibilities with the space station's microgravity environment requirements; (2) the lack of a compelling business case; and, (3) severe space station program budgetary shortfall problems. Nonetheless, there are strong indications that satellite operators would support the creation of a robust, servicing infrastructure in space. ${ }^{10}$

The lack of an ability to close the business case continues to plague present-day established and entrepreneurial companies that have continued to invest in the development of commercial satellite servicing capabilities. In 2010, a foreign company became the first to announce publicly that it had closed the business case on the design of a GEO refueling servicing capability and would plan to have its first flight demonstration in 2013. Around the same time, the DLR announced that it was granted the authority and would be funded by the German government to demonstrate a satellite servicing capability. In addition, a second foreign company has been very active in the development of a reboost and relocation servicer spacecraft that can operate on existing, nonstandardized, uncooperative spacecraft. This strong foreign/international interest and investment combined with the results of the NASA 2010 "International Workshop on On-Orbit Satellite Servicing," suggest the potential for a governmentsupported, commercial, international race-to-market between 2010 and 2015. This workshop and follow-on studies have identified several American companies that are actively engaged in these pursuits, but are being held at bay by several significant barriers and challenges (discussed in the Part B).

\section{B. Government-Commercial Partnership}

Figure 12 presents a high-level roadmap that could result in the establishment of a LTG infrastructure by 2025, driven by a government-industry or public-private partnership, and commercial industry strategic and international alliances.

It is in the long-term interest of NASA, DoD, and other governmental entities, to build and sustain a healthy commercial space/satellite industry. The U.S. and global economies will remain heavily dependent on a ring of roughly 300 geo-stationary commercial satellites. In the future, military reconnaissance, Global Positioning/Locating Systems (GP/LS), and Communications, Navigation, and Surveillance/Air Traffic Management (CNS/ATM) applications systems will probably increasingly populate medium and low Earth orbits.

Planning is underway in all sectors, civil, military, commercial and industrial to coordinate a strategy for the future. There is a growing interest within both the defense and commercial sectors in the development of a robotic, satellite-servicing sector, along with various high-risk satellite technologies - such as laser/optical systems. This prospect appears ideal as both a necessary capability and a potential economic foundation to support NASA's longrange exploration objectives.

Commercial, robotic, in-space servicing is expected to find an initial foothold or market in GEO ${ }^{11}$. As mentioned earlier, the key to this and any space market was identified as standardization. If satellite/spacecraft manufacturing

\footnotetext{
${ }^{9}$ NASA decided to develop a \$288-million Flight Telerobotic Servicer in 1987 after Congress voiced concern about American competitiveness in the field of robotics. The FTS would also help astronauts assemble the Space Station, which was growing bigger and more complex with each redesign. Martin Marietta and Grumman received \$1.5-million study contracts in November 1987. Martin Marietta received a \$297-million contract in May 1989 to develop a vehicle by 1993. The Bush Administration briefly tried to commercialize the FTS project in early 1989. The contractors objected since the FTS had no commercial customers. The FTS was then combined with the Orbital Maneuvering Vehicle into the Robotic Satellite Servicer concept. (Source: http://www.astronautix.com/craft/flivicer.htm)

${ }^{10}$ Reference 3, Appendix B, Questions 12, 13, 14, 15.

${ }^{11}$ Reference 3, Appendix B, Question 20
} 


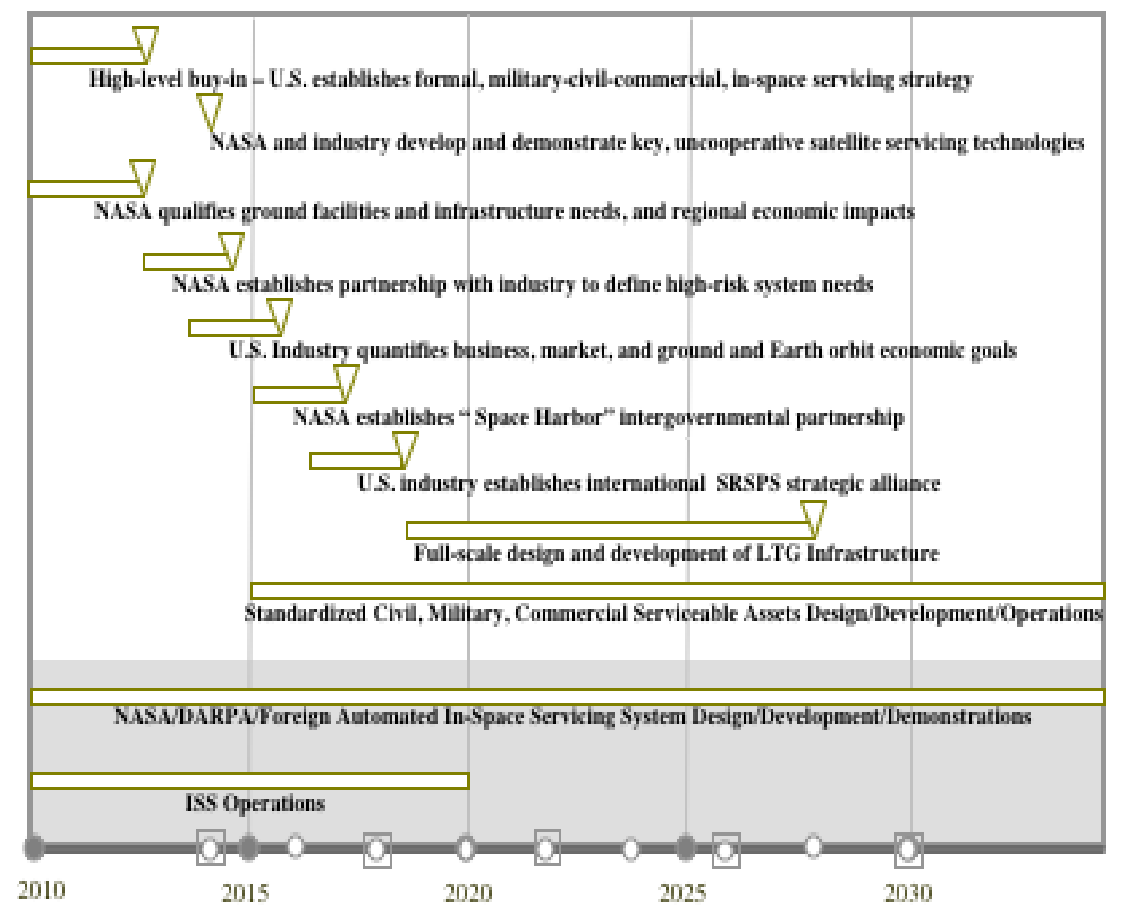

Figure 12.-Notional high-level roadmap for the systematic realization of a LTG satellite-servicing infrastructure by 2025-a civil-to-commercial transition strategy for major sub-systems.

were standardized (i.e., component interfaces, dimensions, etc.), as a result of market forces or government regulation, then it is conceivable that the (Earth orbit) market for spacecraft/satellite servicing (and protection) could rapidly grow into the hundreds of billions of dollars. This could become a thriving industry with no real limits to the growth-stage, given the potential for development and deployment of serviceable (Earth-Moon or Sun libration points) exploration and other spacecraft.

Outside the United States there is a strong and growing interest in the establishment of satellite information networks to provide a variety of services ranging from global positioning to remote sensing. There is growing concern in the U.S. space industry that it is losing market share in the satellite manufacturing and launch vehicle services sectors. This is primarily being blamed on other countries' subsidies to their emerging space industries. That being said, it is clear that the 21 st century holds the promise of the potential emergence of a large international market for robotic, on-orbit servicing that would effectively dwarf the present global satellite industry. Europe, through the ESA is partnered with the U.S. in the construction of the ISS. ESA is also poised to expand its reliance on satellite networks in the future for emerging services such as navigation, telemedicine, high value asset tracking, etc.

Like Europe, Japan has also engaged in long-range planning for 21 st century space investments driven by both science exploration and commerce. There is also significant interest in space in the developing world. In addition to India as a new player in long-range space planning, the Chinese have made a strong commitment to future space investment. From Europe, to Japan, to China, to India therefore, it appears that during the early-to-mid 21st century, attention will increasingly be focused on significant development of satellite/spacecraft systems. Clearly, such systems will be spawned from the fertile and potent interests of nations driven by the quest for new knowledge, resources, and the fundamental need to prove the plurality of life in the universe. Based on the above indicators, it is reasonable to expect that the market for a future development of a robust, robotic, in-space servicing infrastructure will rest not only on the formation of a strong collaboration between U.S. civil, military, commercial and industrial concerns, but also on strong international cooperative interests. 
As mentioned previously, recent studies within NASA have resulted in the preliminary definition of the following five near-term "commercial in-space servicing" market sectors: (1) Propellant Transfer and Depot/Storage; (2) Satellite Servicing (i.e., Repair, Maintenance, Refueling, etc.); (3) Orbital Transportation/Transfer; (4) On-orbit Assembly; (5) Orbital Debris Removal/Mitigation. Table 2 shows the complete list of barriers and challenges faced by both established and entrepreneurial companies seeking to jumpstart the new, high potential, commercial in-space servicing industry. This study process identified the four highestpriority barriers and challenges facing each sector. The satellite-servicing sector had the following: (1) Investment Risk, (2) Market/Customer Risk; (3) ITAR/National Security Risk; and (4) Liability/Insurance Risk. NASA is currently planning to actively seek solutions to help U.S. industry eliminate/overcome these and other barriers and challenges.

TABLE 2.-COMMERCIAL IN-SPACE SERVICING BARRIERS AND CHALLENGES IDENTIFIED IN NASA 2010 STUDY

\begin{tabular}{|ll|cl|}
\hline \multicolumn{2}{|c|}{ Barriers } & \multicolumn{2}{c|}{ Challenges } \\
\hline 1. & Bilateral Agreement & 1. & Financing \\
\hline 2. & Multilateral Agreement & 2. & Geopolitical Risk \\
\hline 3. & International Treaty & 3. & Investment Risk/DDT\&E \\
\hline 4. & IRR/ROE & 4. & Lack of Export Financing \\
\hline 5. & ITAR/National Security & 5. & Lack of Investor/Owner/Operator \\
\hline 6. & Lack of NASA/Gov't Commitment & 6. & Liability/Insurance Risk \\
\hline 7. & Propellant Launch Cost & 7. & Market/Customer Risk \\
\hline 8. & Property Rights & 8. & Misconception of Technology \\
\hline & & 9. & NASA/Gov't Risk - Customer or Competitor \\
\hline & 10. & Political Risk \\
\hline & 11. & Technical Risk \\
\hline & 12. & Traffic Coordination \\
\hline & 13. & Traffic Regulation \\
\hline
\end{tabular}

The shift from a 20th century build-launch-operate-replace (BLOR) ${ }^{12}$ to a 21 st century build-launch-operateservice-protect (BLOSP) mindset or philosophy for future civil-military-commercial space systems is considered an inevitability that might be justified on the basis of establishing a robust, cost-effective, space-based servicing infrastructure for 21 st century spacecraft. Toward this end, entrepreneurial investment activity in this area has continued at a very low, self-supporting level. Given the considerable barriers and challenges involved, the establishment of a robust, in-space, robotic satellite-servicing industry sector should probably be catalyzed through a government-led initiative. This would stimulate commercial activity and evolve into a potentially strong economic foundation for space development and exploration, with perhaps numerous, unforeseeable, serendipitous economic development offshoots in space. In other words, this may be the way to achieve an economic, self-sufficient, space enterprise that can be used to reduce or minimize dependence on the public/tax-based component of investment in space development and exploration.

Past studies ${ }^{13}$ on the economic viability of servicing for GEO, MEO, and/or LEO spacecraft have largely endorsed the prospects through analyses of its cost effectiveness compared to expendable satellites. Several studies and articles have focused on assessing the viability of discrete market segments (repair, refueling, etc.). As a comparison, commercial and other economic, social, and defense activities grew and expanded around the world as a result of highway and various, public and/or private capital infrastructure investments. Likewise, increasingly profitable in-space servicing and other market/business activities can be expected to emerge and thrive after a costeffective, government and/or industry-led, commercially operated infrastructure is established.

\section{Alignment With New U.S. Space Policy}

The new National Space Policy of the United States, alluded to in Section I, continues the U.S. global leadership posture and contains several related goals, which clearly suggests that the new strategy for the development of space will involve an increasing dependency on privately funded commercial space activities and international cooperation. These goals are stated as follows:

\footnotetext{
${ }^{12}$ Reference 3, Appendix B, Question 1

${ }^{13}$ Reference 3-References: Sullivan, 2001; Madison, 1999; Levin, 1993; Space Systems Loral, 1990; Chenard, 1990; Higginbotham, 1987.
} 
"Energize competitive domestic industries to participate in global markets and advance the development of: satellite manufacturing; satellite-based services; space launch; terrestrial applications; and increased entrepreneurship.

Expand international cooperation on mutually beneficial space activities to: broaden and extend the benefits of space; further the peaceful use of space; and enhance collection and partnership in sharing of space-derived information.

Strengthen stability in space through: domestic and international measures to promote safe and responsible operations in space; improved information collection and sharing for space object collision avoidance; protection of critical space systems and supporting infrastructures, with special attention to the critical interdependence of space and information systems; and strengthening measures to mitigate orbital debris.

Increase assurance and resilience of mission-essential functions enabled by commercial, civil, scientific, and national security spacecraft and supporting infrastructure against disruption, degradation, and destruction, whether from environmental, mechanical, electronic, or hostile causes.

Pursue human and robotic initiatives to develop innovative technologies, foster new industries, strengthen international partnerships, inspire our Nation and the world, increase humanity's understanding of the Earth, enhance scientific discovery, and explore our solar system and the universe beyond."

It will probably remain the responsibility of the United States to continue its leadership of the world in space throughout most of the 21st century. European and Asian countries are rapidly integrating and/or transforming their respective economies and thus might assume a significant share of space leadership and power later in this century. However, given current political and economic realities, it is becoming increasingly apparent that every step we propose to take in space, whether for exploration or development, must minimize and simultaneously reduce dependence on taxpayer dollars. The new U.S. space policy appears to embrace and fully recognize this reality in its strong and unambiguous promotion of commercial space and international cooperation as major factors for success in all space-related endeavors in the future. The LTG-related goals and objectives offered in this paper are also clearly aligned with and in support of this new policy.

Over the last 52 years, since its inception, NASA has worked to realize national space policy and meet its statutory obligations. ${ }^{14}$ The agency has transitioned, developed and/or introduced various systems and technologies into civil and commercial use. This began with the transitioning of military expendable launch vehicle technologies during the late 1950s and early 1960s, which culminated in the Apollo/Moon program success. NASA then graduated to partially reusable launch vehicle technology in the form of an ambitious shuttle STS program in the 1970s. Throughout the shuttle program, the agency amassed an impressive record of accomplishments by pushing back the boundaries of knowledge in the material sciences, life sciences, and biomedical and bioengineering disciplines. Much more remains to be accomplished, and with the advent of the International Space Station (ISS), the civil infrastructure development of LEO will continue to progress onward.

In meeting its policy and statutory obligations, NASA also created the satellite industry. This industry has become one of the most critical capabilities of paramount, strategic military and economic importance to the purposes and objectives of modern, global civilization. In addition to several high-value scientific spacecraft such as the Hubble

\footnotetext{
${ }^{14}$ The National Aeronautics and Space Act of 1958. Section 102 (b) states that "The Congress declares that the general welfare and security of the United States require that adequate provision be made for aeronautical and space activities. The Congress further declares that such activities shall be the responsibility of, and shall be directed by, a civilian agency exercising control over aeronautical and space activities sponsored by the United States, except that activities peculiar to or primarily associated with the development of weapons systems, military operations, or the defense of the United States (including the research and development necessary to make effective provision for the defense of the United States) shall be the responsibility of, and shall be directed by, the Department of Defense; and that determination as to which such agency has responsibility for and direction of any such activity shall be made by the President in conformity with section 201(e)." Section 102 (c), requires NASA to "seek and encourage to the maximum extent possible, the fullest commercial use of space." This is followed by Section 102 (d) (1), which requires NASA to contribute materially to "the expansion of human knowledge of the Earth and of phenomena in the atmosphere and in space."
} 
Space Telescope (HST) in LEO, there are presently around 300 commercial communications satellites in GEO. There are also several military reconnaissance and GPS satellites operating in MEO. Planning is underway in all sectors, civil, military, commercial and industrial, to establish new satellite networks in the future. In addition, NASA has plans for an ambitious exploration program that will require the installation of large scientific platforms throughout Earth-Moon space and beyond. It is becoming increasingly apparent that the total value of assets to be installed and operated in space during the 21st century, by either government or private interests, could be in the hundreds of billions of dollars. The magnitude of this potential investment implies that the capability to service spacecraft and satellites by robotic means will become increasingly economical, from a cost-effectiveness, asset value, revenue potential, and human safety or risk minimization standpoint.

\section{Conclusion}

In-space, automated or robotic servicing (and protection) through a large-scale, on-orbit infrastructure is considered as a potentially viable industry or economic technology activity. Such activity might effectively and efficiently connect future space enterprise and space exploration with real economic growth contributions. Most importantly, economic growth contributions from the space sector are necessary to increase the relevance of space in the public mind. Given the magnitude and clear potential of this opportunity, it is possible that within the context of the new "flex path" space policy, the core, 21st century United States and international space strategies could be revectored toward the development of a LTG-and-beyond, robotics-centered stepping stone. The satellite industry is mature and ready to be incorporated into this strategy with the right incentives resulting from a government-industry partnership, and the integration of common civil, military, and commercial interests in eliminating/reducing the critical barriers and challenges to industrial growth and success. Preliminary assessments of robotic command, communications, and control, and electric propulsion operations provided encouraging indications. At a more fundamental level, the technical and economic feasibility in terms of BLOSP versus BLOR, technology readiness, in-space operations, and the start-up cost of a robust LTG infrastructure enterprise need to be examined in detail. 



\section{Appendix $^{15}$}

\section{In-Space Robotics Communications and Control}

Figure 13 presents the remote robotic operations latencies for several zones in space. Conventional orbital robotic operations, be it on the Shuttle or the International Space Station, rely on proximity teleoperations controlled by on-board astronauts. The Shuttle Remote Manipulator (SRMS) AFT Flight Deck Robotic Display and Control Station, has operated flawlessly on the Shuttle fleet for nearly 30 years, as well as the Robotic Workstation (RWS) for the International Space Station (ISS). The RWS (see Fig. 14) is the primary on-orbit operator interface for Space Station robotic elements and provides control and televised viewing of Space Station assembly and operations. The RWS was launched on STS-102 and delivered on-orbit in March 2001, and was brought into active service immediately. Since then it has been in almost continuous use. Both of these human-in-the-loop teleoperation systems have the advantage of real-time control and viewing.

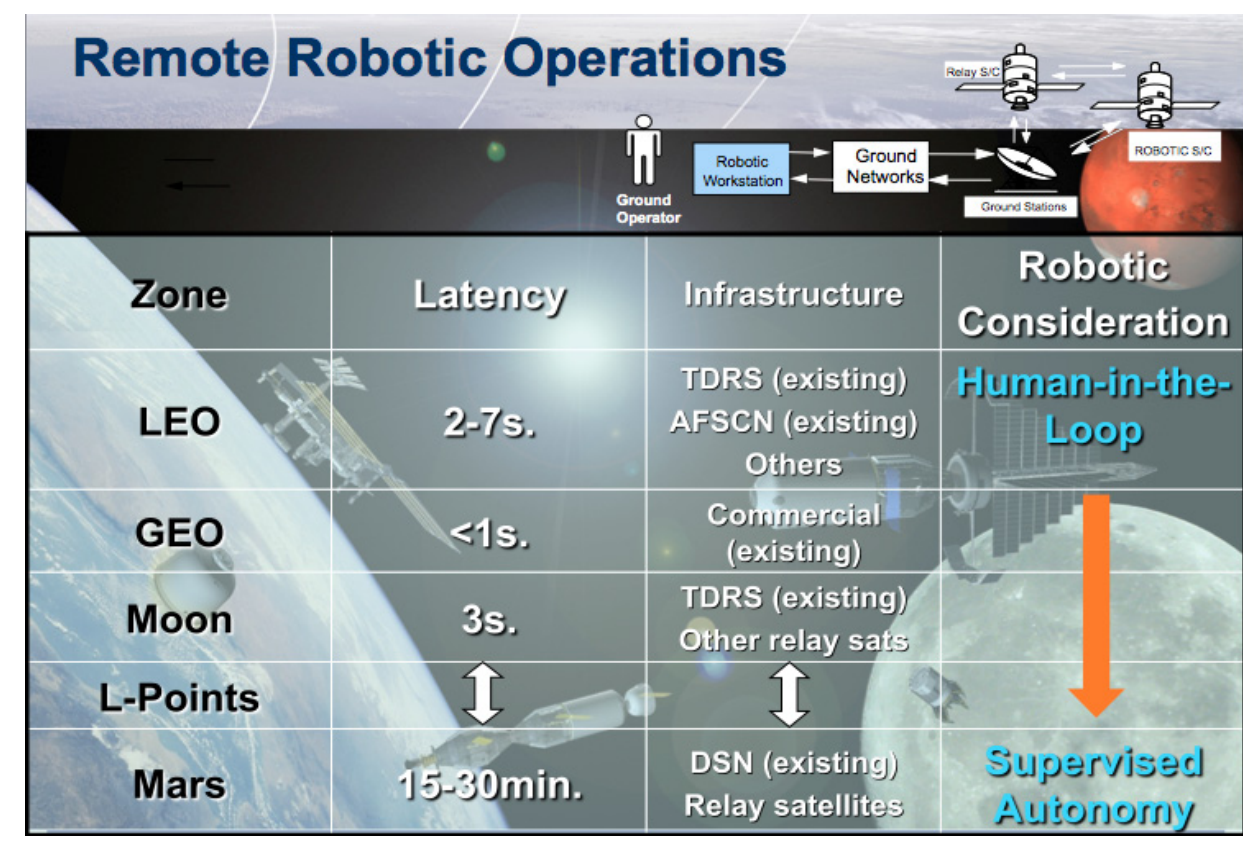

Figure 13.--Remote robotic operations latencies for several zones in space.

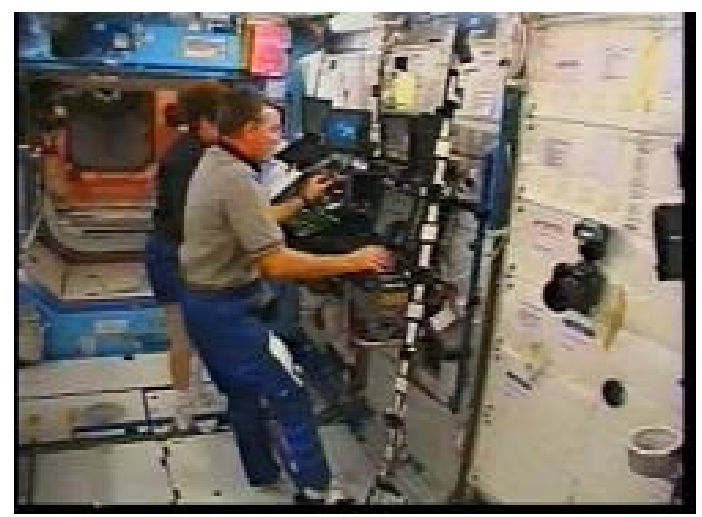

Figure 14.-ISS robotic workstation.

\footnotetext{
${ }^{15}$ The information in this Appendix was obtained from Mr. Dan King, Director, Orbital Robotics, MacDonald, Dettwiler \& Associates.
} 
However, as new Exploration missions operate in an unmanned environment or are conducted over long distances, data communication latency becomes a significant problem and direct human-in-the-loop control may not be possible. Human in the loop control of manipulators is known to degrade when round trip communication latencies exceed roughly 0.25 to $0.5 \mathrm{sec}$. In the case of Mars missions, the data communication latency ranges from roughly twenty to forty minutes, exceeding a duration that would allow direct human-in-the-loop control of any kind. As a consequence, autonomous capabilities have to be introduced. The level of autonomy depends on the complexity of the operation, circumstances and environment under which it will be performed.

For more recent robotic operations such as ISS robotics ground control, an approach called Remote Operation for Supervised Autonomy (ROSA) has been implemented. The same approach was implemented for DARPA's Orbital Express Flight Demonstration flown in 2007. ROSA can provide astronauts and operators on the ground with the ability to choose the level of autonomy with which to instruct the system to perform an operation, and to permit the operator to generate Operations Scripts that seamlessly incorporate mixtures of high and low level commands within a single operation. An operations script can be generated any time prior to the operation. It will, in general, contain a mixture of goals or tasks and low level commands that control the operation. The use of goals to the greatest extent possible simplifies operations planning. In preparation for an operation the script and appropriate models are loaded. During execution the crew may view the operation. However, the crew need not directly control the execution, but maintains the ability to interfere as required. Since human operators can be involved in command and control, autonomous operations can be limited to very short operation at a time, significantly mitigating the level of risk involved. Architecturally ROSA consist of: 1) sensors to determine the external environment and system state, 2) a behavioral executor to guide operations, 3) an inference engine that invokes and terminates behaviors, 4) an intelligent operations supervisor that controls operations based on high level goals, and 5) a planning and cognitive modeling engine. ROSA has been demonstrated to be capable of effectively operating even with a communications latency of up to 7 to $8 \mathrm{sec}$.

As orbital robotic missions become even more complex, the need for more capable robotic control ground stations arises. One particular example is in the area of robotic operations mission planning, training, monitoring and control. The current approach involves multiple teams at multiple sites performing primarily sequential tasks in the process. In addition, the current generation of robotic control stations is only capable of controlling one robot at a time and largely incapable of command and control of multiple robots active simultaneously while performing cooperative tasks. Such an approach will not be adequate to support anticipated future missions such as in-space assembly, maintenance and servicing of large spacecraft and infrastructure; and surface exploration and construction. Hence a logical next step is to develop a multirobot control ground planning, training, monitoring and control infrastructure. Such an approach will enable the control and oversight of multiple robots working cooperatively amongst themselves or in the presence of astronauts, as well as the efficient planning and training for safe operations. In addition, such a ground station concept will enable a more centralized approach to orbital robotic operations.

Further into the future, a reasonable goal for autonomy in future human space exploration systems and operations is a range of autonomy rather than an absolute level. A system that supports variable and enhanced levels of autonomy is required. Autonomy will allow the crew to focus on key mission goals where man's cognition, judgment, and experience provide the greatest benefit. Humans will be augmented and enhanced by: improved situational awareness, a system which supports variable levels of autonomy allowing operations to be defined in terms of simple high level goals where applicable, and the elimination of the need to perform routine operations. This will ultimately improve safety, increase efficiency, and reduce mission cost.

\section{References}

1. NASA Headquarters, "Commercial Space Workshop, Commercial In-Space Servicing Working Group Report," July, 2010, URL: https://minx.arc.nasa.gov/minx/dsweb/View/Collection-12851 [cited 8 August, 2010].

2. NASA Goddard, "International Workshop on On-Orbit Satellite Servicing," March 2010, URL: http://servicingstudy.gsfc.nasa.gov/ [cited 8 August, 2010].

3. Horsham, G.A.P., "Envisioning a 21 st Century, National, Spacecraft Servicing and Protection Infrastructure and Demand Potential: A Logical Development of the Earth Orbit Economy," NASA/TM-2003-212462.

4. Obama Administration, "National Space Policy of the United States of America," June 28, 2010.

5. Review of Human Spaceflight Plans Committee, "Seeking a Human Spaceflight Program Worthy of a Great Nation," October 2009.

6. Gilland, J.H., "Commercial Electric Propulsion Implications for NASA Missions," Presented at the JANNAF 3rd Spacecraft Propulsion Subcommittee Joint Meeting, Orlando, FL, Dec. 2008. 
7. Patterson, M., Pinero, L., and Sovey, J., "Near-Term High Power Ion Propulsion Options for Earth- Orbital Applications," AIAA Paper 2009-4819.

8. Jacobson D., and Manzella, D., "50 kW Class Krypton Hall Thruster Performance," AIAA Paper No. 20034550.

9. Busek Corp., "Busek Hall Thruster Demonstrates 20 kW Dual Mode Operating Capability," 2010.

10. Gilland, J., Fiehler, D., and Lyons, V., "Electric Propulsion Concepts Enabled by High Power Systems for Space Exploration," IECEC Paper No. 22208, AIAA-2004-5690, 2nd International Energy Conversion Engineering Conference, Providence, RI August 2004.

11. Spores, R. et al., "A Solar Electric Propulsion Cargo Vehicle to Support NASA Lunar Exploration Program," IEPC-2005-320, Princeton, NJ, Oct. 2005.

12. Eskenazi, M. et al., "Promising Results From Three NASA SBIR Solar Array Technology Development Programs," NASA/CP-2005-213431, 2005.

13. O'Neill, M. et al., "Stretched Lens Array (Sla) For Solar Electric Propulsion (SEP)," Presented at the 20th Space Photovoltaic Research and Technology (SPRAT XX) Conference September 25-27, 2007, Cleveland, Ohio.

14. Futron Corporation for the Satellite Industry Association, "2010 State of the Satellite Industry Report," June 2010.

15. Department of Commerce, International Trade Administration, "Flight Plan 2009: Analysis of the U.S. Aerospace Industry," March 2009.

16. Maléter, A., "Strategies to Mitigate High Satellite Insurance Premiums," Satellite Finance, Issue 64, December 2003.

17. U.S. Aerospace Commission, "Final Report of the Commission on the Future of the United States Aerospace Industry-Anyone, Anything, Anywhere, Anytime," November 2002. 
The public reporting burden for this collection of information is estimated to average 1 hour per response, including the time for reviewing instructions, searching existing data sources, gathering and maintaining the data needed, and completing and reviewing the collection of information. Send comments regarding this burden estimate or any other aspect of this collection of information, including suggestions for reducing this burden, to Department of Defense, Washington Headquarters Services, Directorate for Information Operations and Reports (0704-0188), 1215 Jefferson Davis Highway, Suite 1204, Arlington, VA 22202-4302.

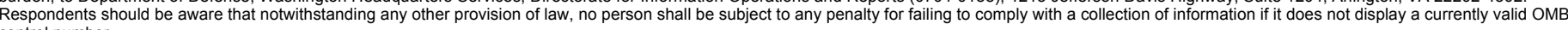

PLEASE DO NOT RETURN YOUR FORM TO THE ABOVE ADDRESS.
1. REPORT DATE $(D D-M M-Y Y Y Y)$
2. REPORT TYPE
3. DATES COVERED (From - To)

$01-11-2010$

Technical Memorandum

\title{
4. TITLE AND SUBTITLE
}

Establishing a Robotic, LEO-to-GEO Satellite Servicing Infrastructure as an Economic

Foundation for Exploration

5a. CONTRACT NUMBER

5b. GRANT NUMBER

5c. PROGRAM ELEMENT NUMBER

\section{AUTHOR(S)}

5d. PROJECT NUMBER

Horsham, Gary, A.P.; Schmidt, George, R.; Gilland, James, H.

\section{5e. TASK NUMBER}

5f. WORK UNIT NUMBER

WBS 736466.01.08.03.03.01

\section{PERFORMING ORGANIZATION NAME(S) AND ADDRESS(ES)}

National Aeronautics and Space Administration

8. PERFORMING ORGANIZATION

John H. Glenn Research Center at Lewis Field

REPORT NUMBER

Cleveland, Ohio 44135-3191

E-17541

9. SPONSORING/MONITORING AGENCY NAME(S) AND ADDRESS(ES)

National Aeronautics and Space Administration

Washington, DC 20546-0001

\author{
10. SPONSORING/MONITOR'S \\ ACRONYM(S) \\ NASA
}

11. SPONSORING/MONITORING REPORT NUMBER

NASA/TM-2010-216937

\section{DISTRIBUTION/AVAILABILITY STATEMENT}

Unclassified-Unlimited

Subject Category: 99

Available electronically at http://gltrs.grc.nasa.gov

This publication is available from the NASA Center for AeroSpace Information, 443-757-5802

\section{SUPPLEMENTARY NOTES}

\section{ABSTRACT}

The strategy for accomplishing civilian exploration goals and objectives is in the process of a fundamental shift towards a potential new approach called "Flexible Path." This paper suggests that a government-industry or public-private partnership in the commercial development of low Earth orbit to geostationary orbit (LEO-to-GEO (LTG)) space, following or in parallel with the commercialization of Earth-to-LEO and International Space Station (ISS) operations, could serve as a necessary, logical step that can be incorporated into the flexible path approach. A LTG satellite-servicing infrastructure and architecture concept is discussed within this new strategic context. The concept consists of a space harbor that serves as a transport facility for a fleet of specialized, fully- or semi-autonomous robotic servicing spacecraft. The baseline, conceptual system

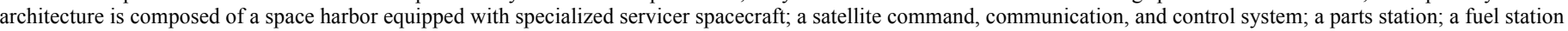
or depot; and a fuel/parts replenishment transport. The commercial servicer fleet would consist of several types of spacecraft, each designed with specialized robotic manipulation subsystems to provide services such as refueling, upgrade, repair, inspection, relocation, and removal. The space harbor is conceptualized as an ISS-type, octagonal truss structure equipped with radiation tolerant subsystems. This space harbor would be primarily capable of serving as an operational platform for various commercially owned and operated servicer spacecraft positioned and docked symmetrically on four of the eight sides. Several aspects of this concept are discussed, such as:

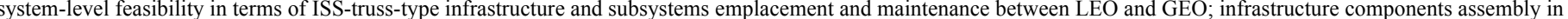
LEO, derived from ISS assembly experience, and transfer to various higher orbital locations; the evolving Earth-to-orbit (ETO) capability to deliver humans and cargo to LEO for assembly purposes; system architectural definition, optimal orbital parameters, mass estimations, delta velocity ( $\Delta V$ ) estimations, power and propulsion options, and assessments of various critical technologies. Large-scale, robotic, LTG satellite servicing is considered as an essential economic pre-condition and next parallel or sequential step on the road toward exploration beyond LEO. Such a step might produce the necessary pre-requisite economic value that can be used by future decision makers to justify further investment in exploration beyond LEO

\section{SUBJECT TERMS}

Orbital servicing; Spacecraft maintenance; Robotics; Telerobotics; Space commercialization; Commercial Spacecraft; International Space Station; Space platforms; Large space structures; Electric propulsion; Low Earth Orbit (LEO); Geosynchronous orbit

\begin{tabular}{|c|c|c|c|c|c|}
\hline \multicolumn{3}{|c|}{ 16. SECURITY CLASSIFICATION OF: } & \multirow{2}{*}{$\begin{array}{l}\text { 17. LIMITATION OF } \\
\text { ABSTRACT }\end{array}$} & \multirow{2}{*}{$\begin{array}{l}\text { 18. NUMBER } \\
\text { OF } \\
\text { PAGES } \\
24\end{array}$} & \multirow{2}{*}{$\begin{array}{l}\text { 19a. NAME OF RESPONSIBLE PERSON } \\
\text { STI Help Desk (email:help@sti.nasa.gov) } \\
\text { 19b. TELEPHONE NUMBER (include area code) } \\
\text { 443-757-5802 }\end{array}$} \\
\hline $\begin{array}{l}\text { a. REPORT } \\
U\end{array}$ & $\begin{array}{l}\text { b. ABSTRACT } \\
U\end{array}$ & $\begin{array}{l}\text { c. THIS } \\
\text { PAGE } \\
\text { U }\end{array}$ & & & \\
\hline
\end{tabular}



